\title{
Thematic branding of regional hotels in the competitive market of the network business (on the example of Siberian and North Western Federal districts)
}

\author{
Olga Arkhipova ${ }^{1}$, Yulia Vladykina $^{2}$, Natalya Donets ${ }^{2, *}$, Olga Osipova $^{2}$, and Galina \\ Uryupina $^{2}$ \\ ${ }^{1}$ Saint-Petersburg state University of Economics, 21, Sadovaya str., 191023, Saint-Petersburg, Russia \\ ${ }^{2}$ Saint-Petersburg State Agrarian University, 26, Peterburgskoe shosse, 196601, Pushkin, Saint- \\ Petersburg, Russia
}

\begin{abstract}
The modern point of development of tourist destinations forming a tourist traffic, generating regular local budgetary income and developing social infrastructure is the search for local authenticity. Expressed in all visual interpretations, including the brand, it allows you to "launch" regions having completely different initial conditions and make them be investment attractive. A unique selling proposition, built taking into account the incorporation of a territorial brand into the overall architecture, allows hotel enterprises to fully function in the high-risk and highly competitive market of hotel chains.
\end{abstract}

\section{Analysis of the tourist flow in Russia}

Projected in the late 90's growth of tourist traffic and Russia's entry into the TOP 20 [1] countries of tourist arrival, today gives $15-19 \%$, and according to some expert estimates 20 $25 \%$ of the annual growth of tourists. The main tourist arrivals are citizens of China, Germany, South Korea, Iran, India (Fig.1), promising countries can be considered Canada, the US, France, Italy, Britain, Finland and a number of other [7]. In quantitative terms, the total domestic tourist flow in Russia in 2019 is expected to reach 30 million people. and above, especially in the Eastern part of the country, through the introduction of electronic visas and the facilitation of border crossing $[2,3]$.

\footnotetext{
*Corresponding author: doniya-nata@mail.ru
} 


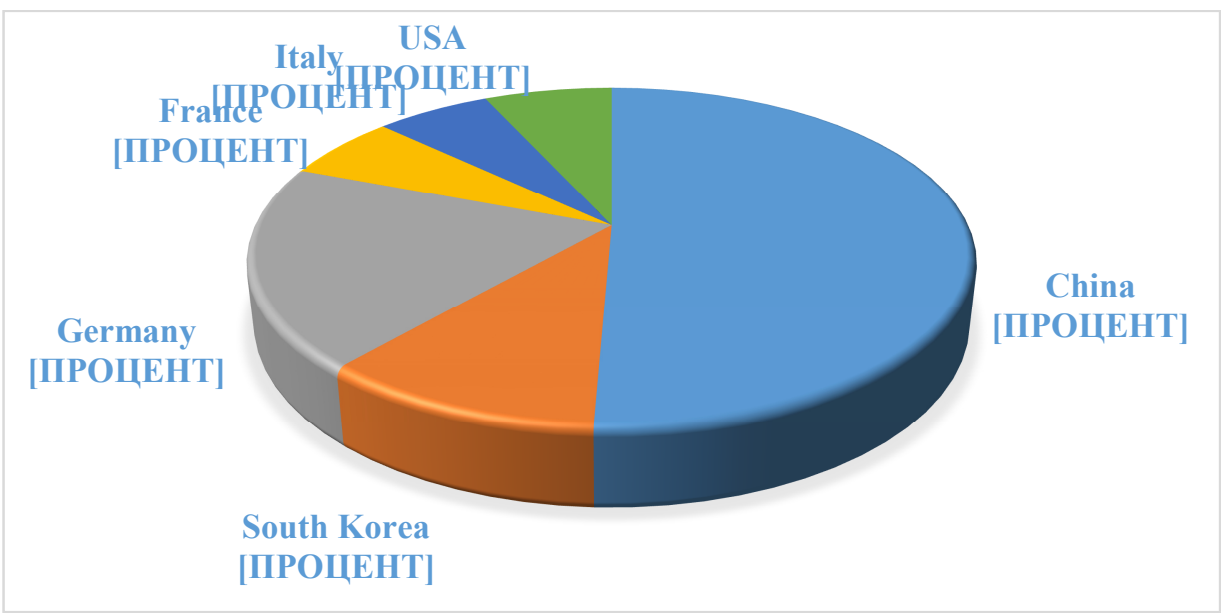

Fig. 1. The formation of tourist arrivals of foreign tourists in Russia, $2018[3,7]$.

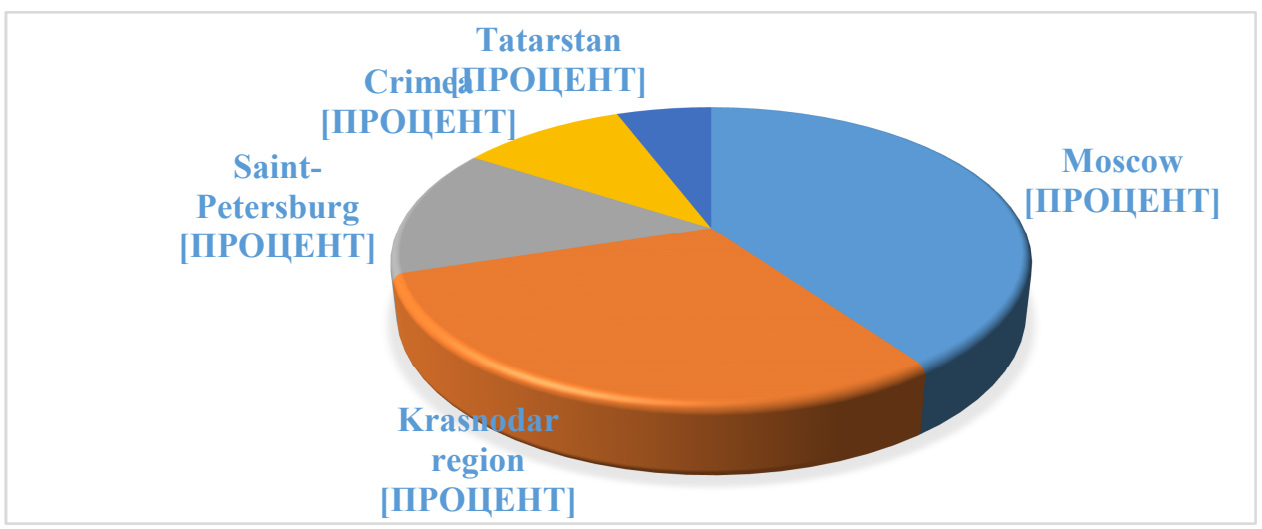

Fig. 2. The distribution of the total tourist arrivals by Russia region, 2017 [2,3,7].

However, if we take into account that 25-30 million people of potential tourists, of which only $30 \%$ are entry, are rather unevenly distributed across the territories, preferring Moscow and St. Petersburg (up to $75 \%$ of the total tourist traffic and the remaining $25 \%$ on the known natural and recreational destinations of the international level (Baikal, Kamchatka, etc.), it becomes obvious that regional tourist destinations can only rely on business trips or the activity of potential destinations with the launch of "at the same timeobjects" to increase and stabilize the flows. Under these conditions, the inclusion of hotel chain operators in the competition (Ibis, Hilton, Radisson, etc.), especially with the offers of the economy class line, does not just interfere, but destabilizes the work of local hoteliers, including the complete closure of hotels. Full competition in such conditions is not possible, since "network" use international bases of loyal customers, which are replenished due to a small local demand. Political situations greatly contribute to the increase in domestic demand (Fig. 1)

The priority of choice in the direction of Moscow, St. Petersburg and the resorts of the Black Sea coast is obvious (Fig. 2). Approximately 4.5 million people remain for the regions from the forecast tourist traffic, that is the market of regional hoteliers [3].

The limited tourist flow to the regions is due to both the transport concentration and the standard behavior of a classical tourist "one country- one time", as well as the concentration of attractive objects in capital cities. For regional destinations, a way out of the situation is 
to provide an inventory of opportunities and search for topics of a narrow target segment for long-term work. This assumption is based on the fact that the branded regions are obviously of greater interest among compatriots and foreign tourists. At the same time, a brand that contributes to the formation of tourist flows, as a rule, should affect all aspects of the socio-economic, political, cultural, historical and geographical life of the region.

\section{Influence of the brand on the formation of regional tourist traffic}

There are almost no such regions in finished form. There are several categories of regions according to the degree of brand development. For example, the so-called "Old Guard" [4], the regions and municipalities using the images of the Soviet period which strongly associated with certain types of tourism among Russians, has formed a steady tourist flow for many decades. In addition, there are destinations "Adapters", which include cities and regions where the tourism industry which was based on a specific theme, has lost its popularity with the Russians over the years. As a result, there are attractions, but few tourists. Besides, there are regions of "Hermits", which being unique, remain aloof from the vigorous tourist activity due to the remoteness and high cost of passenger traffic from major Russian cities.

In this article, the Arkhangelsk, Vologda, Novgorod, Pskov, Tomsk and Kemerovo Regions, the Tyva and Khakassia Republics are selected as objects of the "Hidden Reserve" and "Clean Sheet" [4]. The choice of these territories of the North-Western and Siberian Federal Districts is due to the similarity of climatic, transport, logistics, social and economic conditions of operation. The territories of the "Hidden Reserve" really have significant objects of display but do not have powerful advertising support from the past "promotion" from the state and for this reason today they are not too popular among Russians, except for the residents of the regions and their closest neighbors, as well they are not popular among foreign tourists. Here, from the presented, you can consider: Arkhangelsk, Vologda Region, Tyva Republics, Khakassia and others. The territory of the "Clean Sheet" includes cities, districts and regions that have recently started to develop tourism actively and for which the majority of Russian tourists have not developed any coherent ideas yet. This could include the Novgorod, Pskov, Tomsk and Kemerovo regions, distant from the central transport and logistics hubs and preserving a sufficient level of cultural, historical and natural recreational landscapes. Actual tasks for them are not only positioning against the background of similar proposals, explaining the way to destinations and correcting the lack of service stereotype, but also involving the various institutional structures of the economy and society in the formation of territories for investment and life [2].

The objective of this work is to determine the position of local small and medium-sized hotels, allowing them to compete in the mass hotel services market.

The process of self-identification with the help of tourism is also possible through other ways of forming an image. Competition for tourists and investors, through a ready or emerging brand, is far from giving all companies an opportunity to fit into the structure of a destination and maintain an active position. Accommodation facilities, which are an internal part of this process, are usually incorporated into the so-called "general flow" only after serious internal work. Most of the enterprises still prefer to focus on the quality of design, service, investment in advertising, the work of staff, suggesting thereby to consolidate customer loyalty. However, all these methods do not select an object from the general range and do not allow to select a destination as a priority $[4,5,8]$.

The analysis of the degree of development of the brands of territories allowed to make comparative conclusions about the attitude towards flows in quality within the tested 
regions Further, assessments of possible directions of branding of hotel enterprises in the regions were made. The evaluation was carried out by the focus- group method according to the established criteria, the results of the assessment are reflected in the charts (Fig.3,4)

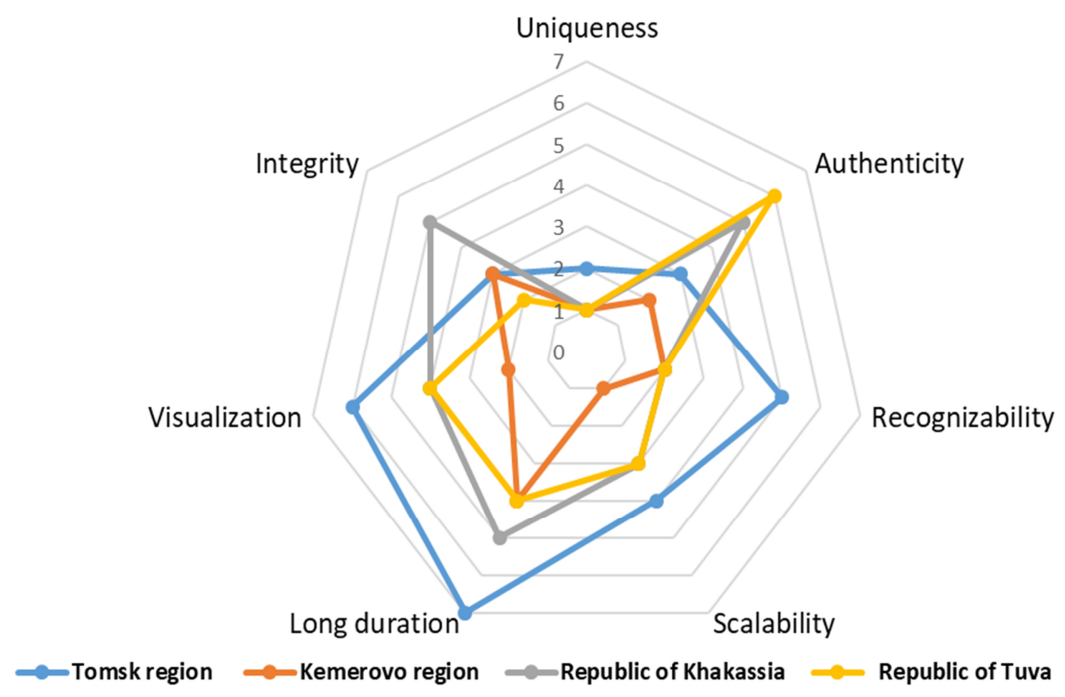

Fig. 3. Assessment of brand formation, regions of Siberian district (1-7 points).

\section{Features and prospects of branding Siberian territories}

The assessment of the territories shows that the Tomsk region is in the lead among the considered regions by the factors "Visualization", "Long-term", "Scalability" and "Recognizability" of the brand. However, being technical components of the brand, the listed characteristics do not make it possible to distinguish the Tomsk region from other Siberian regions in the potential tourists market [4]. At the same time, the bright "Authenticity" and "Integrity" of the republics of Tyva and Khakassia cannot currently be replicable, durable and massively recognizable, since the image of the territory has no visualization and, like most Russian brands, is more a logo than a general idea of the territory [6].

Among the presented criteria for evaluating brands are not the most or least important, since each of them is important in the overall structure and a working brand should have all the characteristics to the full. However, if we comment on the factor of "Authenticity" and "Integrity", then the preservation of the local culture, life and folk traditions characteristic of a given natural geographic destination becomes apparent. Thanks to the transport and informational remoteness of the republics of Khakassia and Tyva, the authenticity factor is fully present so for the tourist promotion of the territory, it is necessary to use the factor of inaccessibility of the territory as part of the adventure and service.

Further, some territories of the Northwestern Federal District were analyzed from the point of view of the existence of a territory brand that influences the formation of a tourist flow. Similarly, an assessment of regional brands was conducted, as the most comparable with the Siberian region on the above signs. It should be noted that such evaluation criteria as "Uniqueness" and "Authenticity" assumed exactly the quality of the territory's brand and not the level of social or cultural development. 


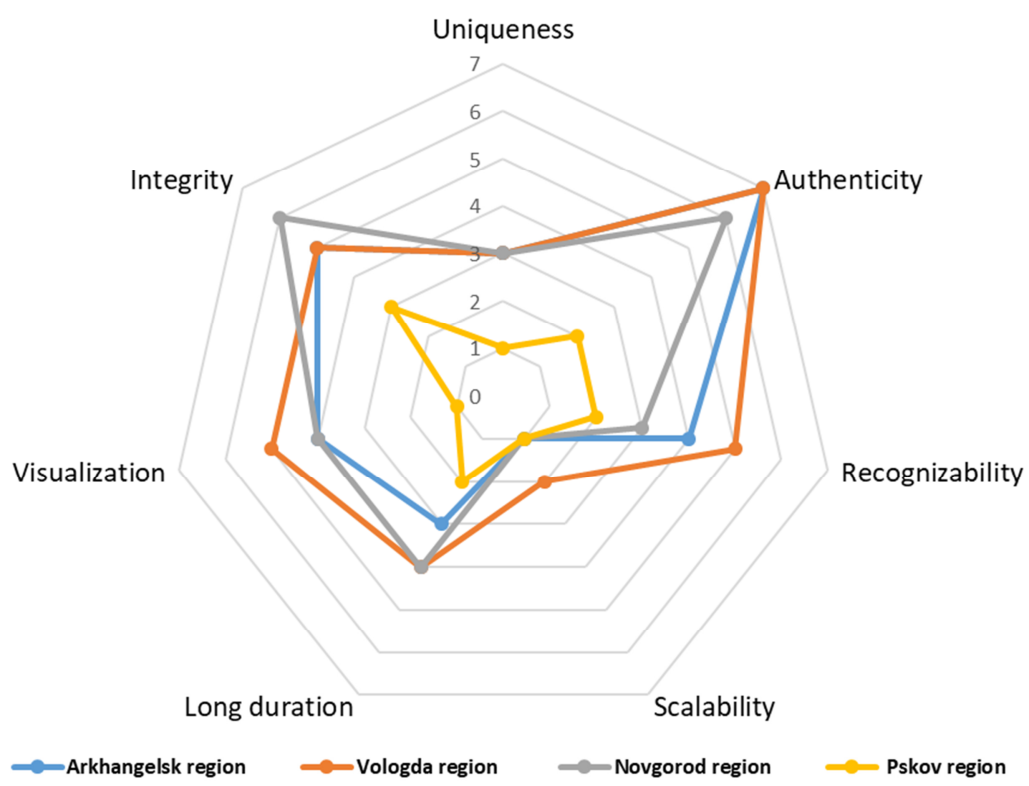

Fig. 4. Assessment of brand formation, regions of North-West Federal district (1-7 points).

\section{Comprehensive approach to promotion of tourist and hotel brands}

Thus, the result of the study showed that the brands of the studied territories are formed spontaneously, without reference to the overall strategy of the region's development, social demands and investment policy. The myths, legends, types of economic activity existing in the territories, the social mentality of the population allows us to offer and develop some areas of branding that do not contradict the emerging images, especially since at the moment these areas are poorly understood and are not widely used in the strategies of the hotel industry. At the same time, in the indicated territories, as well as all other regional centers, there is a process of mass introduction of the network hotel product of Ibis, Best Western, Hilton and other international networks. There is the question of competitiveness with the network sector which has an extensive customer base, sales information service, automated profitability analysis systems, a cumulative base of standardized customer interaction operations, making it quite easy to enter regional markets and crowd out local hotels and hotel enterprises. So, another question appears: how can one compete for domestic tourist traffic without having in store world-promoted signs, investments or subsidies, a system of development, consulting and effective management? The standard answer is: "To urgently form / restore and implement their own standards systems, master the skills of effective network management and replicate business models in internal territories by minimizing fixed and variable costs, etc." The process will take from two to ten years, taking into account the condition of the old number fund and credit rates in commercial banks and the experience of forming international brands from 20-60 years. It is clear that such a strategy will not help. What is the way out?

If we take as a basis the developing "economy of impressions" with non-price competition at the brand level, then the development of strategies of regional hotel enterprises should include the stage of connection (style, theme, strategy) of local hotels to the common brand of the territory, even if it is being formed, through the stage "at the same time-object", like the hotel "Tsarskaia Derevnia" with "Boyarskie Chambers" that exists 
in the successful projects of the Golden Ring (Sergiev Posad), the hotel "Ershov's House" (Gorokhovets)," Pushkarskaya Sloboda" (Suzdal) with subsequent inclusion of the main theme of the territorial destination. This approach is the basis of the competitive regional hotel strategy that is proposed by the authors of this work (Table 1) [5,8].

Table 1. Strategic branding of the regional hotel product.

\begin{tabular}{|c|c|c|c|c|}
\hline Region & $\begin{array}{c}\text { Level of } \\
\text { development of } \\
\text { destination }\end{array}$ & $\begin{array}{l}\text { Direction of the } \\
\text { brand formation }\end{array}$ & $\begin{array}{l}\text { Description of } \\
\text { the brand }\end{array}$ & $\begin{array}{l}\text { Possible hotel } \\
\text { branding } \\
\text { topics }\end{array}$ \\
\hline $\begin{array}{l}\text { Novgorod } \\
\text { region }\end{array}$ & «White sheet» & Initial Russia & $\begin{array}{l}\text { The origins of the } \\
\text { Russian statehood } \\
\text { formation }\end{array}$ & $\begin{array}{l}\text { Birch bark. } \\
\text { The Chronicle, } \\
\text { The Princes, } \\
\text { The Rusichi }\end{array}$ \\
\hline Pskov region & «White sheet» & Guard fortress & $\begin{array}{c}\text { Boundary } \\
\text { territory } \\
\text { protecting the } \\
\text { country }\end{array}$ & $\begin{array}{l}\text { Monastic post, } \\
\text { Watchtower }\end{array}$ \\
\hline $\begin{array}{l}\text { Arkhangelsk } \\
\text { region }\end{array}$ & «Hidden reserve» & \multirow{2}{*}{ Russian north } & \multirow{2}{*}{$\begin{array}{l}\text { Inaccessibility, } \\
\text { Reserve of } \\
\text { Russian } \\
\text { traditional culture } \\
\end{array}$} & \multirow{2}{*}{$\begin{array}{l}\text { Phoenix, } \\
\text { North's Sirin }\end{array}$} \\
\hline Vologda region & «Hidden reserve» & & & \\
\hline Tomsk region & «White sheet» & Primeval taiga & \multirow{2}{*}{$\begin{array}{l}\text { Inaccessibility, } \\
\text { reserve of } \\
\text { Siberian ethno- } \\
\text { identity }\end{array}$} & \multirow{2}{*}{$\begin{array}{c}\text { Hermit } \\
\text { Vasyuganie, } \\
\text { White moss, } \\
\text { Cloudberry }\end{array}$} \\
\hline $\begin{array}{l}\text { Kemerovo } \\
\text { region }\end{array}$ & «White sheet» & Rocky taiga & & \\
\hline $\begin{array}{l}\text { Republic Of } \\
\text { Khakassia }\end{array}$ & «Hidden reserve» & \multirow{2}{*}{ Wild Siberia } & \multirow{2}{*}{$\begin{array}{c}\text { Extreme Survival } \\
\text { Zone }\end{array}$} & $\begin{array}{c}\text { Steppe mogul, } \\
\text { the Saiga }\end{array}$ \\
\hline $\begin{array}{l}\text { Republic of } \\
\text { Tyva }\end{array}$ & «Hidden reserve» & & & $\begin{array}{c}\text { Sayan, } \\
\text { Leopard }\end{array}$ \\
\hline
\end{tabular}

According to experts, the competitive advantage lies precisely in this plane, it allows to take into account the mentality, ethno-identity of culture, to launch existing legends and stories of the territory, to activate tourist traffic destinations; it works properly to preserve the authenticity of the regions, to avoid emasculation of tourist territories (as a result of the last stage of development), to outline the boundaries of possibility for tourists and protect the territory from the costs of increasing globalism.

Information is the connecting link of the tourism industry; therefore, in recent years, the introduction of modern information technologies in the sphere of hospitality has been proceeding at a fast pace. Their distribution significantly transformed the stratification of marketing communications. It should be noted that, based on the features shown above, in particular, the growing role of self-governing organizations and the activity of individuals tourists, many changes are being made nowadays, not so much by structures and institutions as by the activities of people who, due to their life circumstances and biographies, experiment with the opening opportunities of the digital communication environment and use them. Branding hotels can be an effective method in the process of forming competitive advantages, allowing hotels to consciously position themselves in the market of tourist and hotel services, regardless of the lack of sustainable national brands in this field.

\section{References:}


1. 2018 International Tourism Results: the highest in seven years. World Tourism Organisation (UNWTO), https://media.unwto.org/press-release/2018-01-15/2017international-tourism-results-highest-seven-years

2. J. Ahn, K.-J. Back, J. Travel Tour. Mark. https://www.tandfonline.com/doi/full/10.1080/10548408.2017.1358239

(2017)

3. O. Arkhipova, Bulletin of the hospitality industry: scientific collection (St. Petersburg state University publ., SPb, 2018)

4. B. Dai, Y.Y. Jiang, L.Q. Yang, Y.L. Ma, Tour. Trib. 28, 39-45 (2013)

5. A. Faddeenkov, J. Vladykina, 14th International Scientific - Technical Conference APEIE, NSTU 2018, 73-76 (2018) http://apeie.conf.nstu.ru/apeie2018/

6. C. Huang, K. Oh, Q. Zhang, Y.J. Choi, J. Travel Tour. Mark. 30, 662-671 (2013) https://www.tandfonline.com/doi/abs/10.1080/10548408.2013.827544

7. H.H. Im, S.S. Kim, S. Elliot, H. Han, J. Travel Tour. Mark. 29, 385-403 (2012) https://www.tandfonline.com/doi/abs/10.1080/10548408.2012.674884

8. R. Joshi, R. Yadav, J. Vacat. Mark. 21, 305-313 (2017) https://journals.sagepub.com/doi/10.1177/0972262917716763

9. S.S. Kim, J. Moon, J. Choe, J. Conv. Event Tour. 17, 318-342 (2016) https://www.tandfonline.com/doi/full/10.1080/15470148.2016.1151394

10. S. Kladou, M. Kavaratzis, I. Rigopoulou, E. Salonika, J. Destin. Mark. Manag. 6, 426435 (2017) https://www.sciencedirect.com/science/article/pii/ S2212571X16301202?via\%3Dihub

11. Y. Lim, P.A. Weaver, Int. J. Tour. Res. 16, 223-231 (2014) https://onlinelibrary.wiley.com/doi/abs/10.1002/jtr.1920

12. E. Marine-Roig, Sustainability 9, 1425 (2017) https://www.mdpi.com/2071$1050 / 9 / 8 / 1425$

13. C. Wu, C. Funck, Y. Hayashi, Int. J. Tour. Res. 16, 546-555 (2013) https://onlinelibrary.wiley.com/doi/abs/10.1002/jtr.1946

14. M.Y. Wu, P.L. Pearce, Tour. Manag. 43, 22-35 (2014) https://www.sciencedirect.com/science/article/abs/pii/S0261517714000119?via\%3Dih $\mathrm{ub}$

15. S. Zenker, N. Martin, Place Brand. Public Dipl. 7, 32-41 (2011) https://link.springer.com/article/10.1057\%2Fpb.2011.5 